Full length article

\title{
Assessment and communication of the environmental performance of construction products in Europe: Comparison between PEF and EN 15804 compliant EPD schemes
}

\author{
Vera Durão $^{\mathrm{a}, *}$, José Dinis Silvestre ${ }^{\mathrm{a}}$, Ricardo Mateus ${ }^{\mathrm{b}}$, Jorge de Brito ${ }^{\mathrm{a}}$ \\ ${ }^{a}$ CERIS, Instituto Superior Técnico, Universidade de Lisboa, Av. Rovisco Pais, 1, 1049-001, Lisboa, Portugal \\ ${ }^{\mathrm{b}}$ CTAC, University of Minho, Department of Civil Engineering, Campus de Azurém, 4800-058, Guimarães, Portugal
}

\section{A R T I C L E I N F O}

\section{Keywords:}

Environmental labelling

Environmental product declarations (EPD)

Life cycle assessment (LCA)

Product environmental footprint (PEF)

\begin{abstract}
A B S T R A C T
The environmental performance of construction products and assemblies is a determinant factor for the environmental sustainability of buildings. Increasing willingness of stakeholders in the construction sector for green procurement, better-informed decisions and consideration of environmental aspects increase the need of transparent, objective and independent information on the environmental performance of construction products. Environmental product declarations EPD based on the European standard EN 15804 are used in the construction sector since 2012. In parallel, since 2011, the European Commission EC has developed a common method for the assessment of the environmental performance of products: the Product Environmental Footprint PEF. After a pilot phase, the PEF method has evolved, and some updates were published in early 2019. The EN 15804 standard has also been revised, and therefore it is the ideal time to seek the harmonization of Life Cycle Assessment LCA methods. This paper presents a pioneer study applied to the construction sector that focus on the comparison between the PEF method 2019 updated and the EPDs developed according to the Core rules for the product category of construction products presented in EN 15804 EN 15804:2012 + A1:2013, recently updated by EN 15804:2012+A1:2013 + A2:2019.

The comparison was performed by listing and analysing key requirements of both methods and their updates. From the results, it was possible to conclude that the methods have very distinct requirements that make the comparison of results or the alternate use of PEFs and EPDs impossible, for instance, in the decision-making process. This highlights the need of harmonisation and therefore the discussion includes the presentation of a roadmap to update the PEF method and the EN 15804 standard so that results can be more coherent and comparable.
\end{abstract}

\section{Introduction}

Environmental awareness of the effects of pollution and resource depletion leads to increasing demand for environmental information on products and services. The LCA method is widely accepted and wellestablished to quantitatively analyse the environmental impacts of activities related to processes, products or services (EC, 2013a). LCA is an internationally standardised method by ISO 14040 series: ISO 14040 concerning Principles and framework (ISO, 2006a); ISO 14044 concerning the Requirements and Guidelines (ISO, 2006b). LCA allows the quantification of all relevant emissions, resources consumption and of the related environmental impacts associated to any goods (products) or services. This method takes into account a product's whole life cycle: from the extraction of resources, through production, use, and recycling, up to the disposal of the remaining waste (EC - JRC, 2010; ISO, 2006a, b).

Currently, several European standards, developed by the Technical Committee (TC) 350 of the European Committee for Standardization (CEN) (TC350/CEN), are published concerning the assessment of the construction works' sustainability performance in the three sustainability pillars (CEN/TC, 2012a, b; CEN/TC, 2011a, b). Both TC350/CEN and ISO have also developed standards concerning the communication of environmental impacts, namely the EPDs, which aim at providing the construction sector with LCA information on construction materials (CEN/TC, 2013; ISO, 2006c).

EPDs have been used in several sectors and countries before the

\footnotetext{
* Corresponding author.

E-mail addresses: vera.durao@tecnico.ulisboa.pt (V. Durão), jose.silvestre@tecnico.ulisboa.pt (J.D. Silvestre), ricardomateus@civil.uminho.pt (R. Mateus), jb@civil.ist.utl.pt (J. de Brito).
} 
development of specific European sectorial standards or Product Category Rules (PCR). In an evaluation of EPD schemes (Mudgal et al., 2012, it was found that there were already more than 10 EPDs or "EPD like" schemes identified in selected countries. In a sectorial approach, six initiatives were identified for the construction sector. However, the development of specific standards such as ISO 21930 (ISO/TC 59, 2007) and EN 15804 (CEN/TC, 2013) as core set of PCRs for EPDs had allowed the harmonisation of such declarations, namely the latter that is focused in construction products in Europe. The development of the umbrella association of programme operators, the Eco Platform (Eco Platform, 2019), was also based on the existence of a common PCR that allows the mutual recognition of EPDs developed according to EN 15804. Currently, this platform recognises 18 established programme operators that use this standard. It has published more than one thousand EPDs (Eco Platform, 2019) that can be used by stakeholders (building owners, designers, building companies) all over the world, with a special focus on Europe.

In parallel, in 2011, the European Commission (EC) launched the Single Market for Green Products Initiative, in which new methods are proposed as a common way of measuring the environmental performance of products and services: The Product Environmental Footprint (PEF) and the Organisation Environmental Footprint (OEF). PEF and OEF methods are developed in a cross-sectorial approach, also applicable to the construction sector. In 2013, an EC Recommendation was released on the use of common methods to measure and communicate the life cycle environmental performance of products and organisations (EC, 2013b). The PEF initiative had a pilot phase that was concluded in 2018. Both the development of the PEF method and the progress during the pilot phase strongly influenced the revision of the European Standard EN 15804 towards the harmonisation with the PEF method (CEN/ TC 350, 2019). Moreover, following the conclusion of the pilot phase of the PEF initiative, the Joint Research Centre (JRC) published a set of suggestions for updating the method (Zampori and Pant, 2019), named "PEF Guidance Document". These suggestions include the improvement of identified fragilities but also some changes to answer the main discussions raised by the scientific community around this method and to make it closer to the pre-existing standards.

So far, several studies have analysed EPD programmes and their PCR, and compared PEF and EPD methods, to provide information on the environmental performance of products in general (Del Borghi et al., 2019; Manfredi et al., 2015; Minkov et al., 2015; Passer et al., 2015; Subramanian et al., 2012). Specifically for construction materials, discrepancies between different EPD programmes or even between environmental performance assessment and communication methods have been analysed but did not focus on the comparison between PEF and EPDs (Gelowitz and McArthur, 2017; Ströbele and Lützkendorf, 2019). Moreover, critical views were published on the PEF method (Bach et al., 2018; Finkbeiner, 2014), namely pointing discrepancies between PEF and the existing LCA standards or on the use of PEF method in wooden materials (Dolezal and Boogman, 2016). Nevertheless, a comparative analysis of the requirements of EN 15804 and PEF, specifically in the construction sector, which includes the comparison between the current proposal for revising EN 15804 standard (CEN/TC 350, 2019) and the suggestions of the JRC to update the PEF method (Zampori and Pant, 2019), was not developed so far. Such comparison and analysis of the application of each of these methods is the main objective of this paper. Moreover, and considering the revised European standard on construction products' EPDs, it analyses the possible convergence process between the methods.

This paper comprises five sections, including this introduction. The second section describes the present context, evolution and standardisation of the methods analysed (LCA, the communication of environmental performance through Type III environmental declarations, in general and specifically for construction products, and the PEF method). Section 3 presents the methodology for comparison, discussing the criteria used. A detailed presentation and discussion of the results achieved is included in the fourth section. The last section suggests an outlook based on the results and summarises the main conclusions of this research study.

\section{Background}

\subsection{Life cycle assessment method and its evolution}

According to Guinée et al., the first studies that are now recognised as (partial) LCAs date from the late 1960s and early 1970s (Guinée et al., 2010). Since then, and mainly in the decades of 1970-1990, there was a path for the development of the LCA method with diverging approaches, terminologies, and results. Later, during the decades of 1990-2000, the first standards were developed, namely by the international Standardization Organization ISO: ISO 14040, ISO 14041, ISO 14042 and ISO 14043ISO, 2006a. These standards were later revised and aggregated into two: ISO 14040 - Environmental management - Life cycle assessment - Principles and framework ISO, 2006a and ISO 14044 - Environmental management - Life cycle assessment - Requirements and guidelines (ISO, 2006b). However, there was no common agreement on how to interpret some of their requirements. Thus, several approaches were developed considering distinct scope, allocation rules, dynamic LCA, etc. (Guinée et al., 2010), as well as diverse assessment methods (e.g. different classification of material flows, impact categories, and characterisation methods, and discussion on the application of normalisation and weighting steps).

At the European level, the pursuit of sustainability (and life cycle thinking) in several sectors has been a priority for some years, reflected in the main policy documents published, such as thematic strategies and communications from the Commission to the European Parliament. In the construction sector, this issue is highlighted namely by the Communication on Resource Efficiency Opportunities in the Building Sector (EC, 2014) and by the Thematic Strategy for the sustainable competitiveness of the construction sector and its Enterprises (EC, 2012).

In the Thematic Strategy for the Sustainable Competitiveness of the Construction Sector and its Enterprises (EC, 2012), the EC states the need of harmonised indicators, codes and methods to assess the environmental performance of construction products, processes and works. This will allow the concept of sustainable construction to be better understood and more widely used. These assessment tools should ensure a coherent and mutually recognised interpretation of the performance while supporting proper functioning of the Internal Market for construction products and services. In the pursuit of these aims, the EC set some priorities, namely:

- To present initiatives to improve the mutual recognition of environmental performance and risk-assessment methods;

- To support the development of an EU-wide life cycle cost-benefits model for Green Public Procurement and introduce sustainable development principles in regional policy;

- To develop harmonised rules on the declaration of the performance characteristics of construction products concerning the sustainable use of natural resources in the context of the Construction Products Regulation (CPR) (EU, 2011).

\subsection{Communication of Environmental related information in the construction sector - EPDs}

In parallel with the development and implementation of LCA standards, the communication of environmental assessment results has also been the object of standardisation. The International Standardization Organization developed standards referring to several types of environmental declarations:

- ISO 14020 - Environmental labels and declarations. General 
Principles;

- ISO 14021 - Environmental labels and declarations - Self-declared environmental claims (Type II environmental labelling). It standardises environmental declarations for which products do not need to comply with previously defined criteria. These Type II declarations are developed by the production company and are not verified by an independent third party;

- ISO 14024 - Environmental labels and declarations. Environmental Labelling Type I. Principles and procedures. Standardises declarations that qualify the declared product, as they ensure that it complies with a pre-established minimum reference level of environmental performance (defined by the labelling programme), and consists of an instrument aimed at communicating with the final consumer;

- ISO 14025 - Environmental labels and declarations - Type III environmental declarations - Principles and procedures (ISO, 2006c). Standardises EPDs, which do not qualify the product as they do not ensure a given level of performance. Rather, they objectively communicate the results of an LCA study developed according to standardised methods and are usually subject to third party verification.

Nevertheless, ISO 14040, ISO 14044 and ISO 14025 leave space for important methodological choices during the LCA study and the development of an EPD. Therefore, even ISO 14025 compliant EPDs may be not comparable, as shown by several studies (Gelowitz and McArthur, 2017; Subramanian et al., 2012). Thus, besides these ISO standards, standardisation activities were developed specifically for construction products both by ISO and by the European Committee for standardisation (CEN), Technical Commission 350 (CEN/TC 350, 2001), on Sustainability of construction works, to better specify the requirements of EPDs for construction products, namely, in the business to business format:

- ISO 21930 - Sustainability in building construction - Core rules for environmental declarations of construction products and services (ISO/TC 59, 2007);

- EN 15804 - Sustainability of construction works - Environmental product declarations - Core rules for the product category of construction products (CEN/TC 350, 2019);

- EN 15942:2011 - Sustainability of construction works Environmental product declarations - Communication format business-to-business (CEN/TC 350, 2001).

ISO 21930 was initially meant to provide the principles and requirements for type III environmental declarations EPD of building products. It provided a framework and the basic requirements for PCR (ISO/TC 59, 2007) but was not a PCR for this product category. It contained specifications and requirements for the EPD of building products, complementing ISO 14025.

A Programme Operators Consortium (Mazeffa, 2017) states, that comparing ISO 21930 to EN 15804, some concerns arise, namely that:

- EN 15804 and its assumptions was developed specifically for Europe, so ISO 21930 tended to be seen as more appropriate for other geographical areas such as North America;

- ISO 21930 was more flexible in its reporting/structure, which was more attractive to industries;

- ISO 21930 required less detail in the PCRs/EPDs;

- US inventories could not meet the requirements outlined in EN 15804.

After being revised, ISO 21930 (ISO/TC 59, 2017) provides the principles, specifications and requirements to develop an EPD for construction products and services, construction elements and integrated technical systems used in any type of construction works. It now establishes a core set of requirements to be considered as core PCR to develop an EPD for any construction product or service. This new version of ISO 21930 is closer to EN 15804 than the previous one, including:

- The adoption of the EN 15804 module reporting;

- Guidance provided in areas such as functional/declared unit, system boundary, data and quality requirements, reference service life, allocation, comparability, average EPDs, and other critical areas of LCA;

- End-of-life (EOL) modelling (especially module D);

- Accounting and reporting for biogenic carbon, carbonation, radioactive waste, volatile organic compounds (VOC) and product emissions to air, soil and water;

- Guidance on sub-category PCRs.

These standards have supported the development of several EPD programmes worldwide, with a great focus on EN 15804 as a core PCR for construction products in Europe (Minkov et al., 2015). This research work focused mainly on the European standard EN 15804 as a core PCR developed for the European context and used as the main reference for the EPD programmes for construction products in Europe. Some of these are, for instance, the IBU, by the Institut Bauen und Umwelt e. V. (Germany), the Alliance HQE- GBC / Programme FDES INIES (France), the Global EPD by AENOR (Spain), the ITB by the Building Research Institute (Poland) or the DAPHabitat by the Portuguese Habitat Cluster. The European umbrella association of programme operators, the Eco Platform (Eco Platform, 2019), also uses EN 15804 as main reference and criteria for the recognition of the EPD programmes. Together with LCA practitioners, industrial associations and other stakeholders, the Eco Platform ensures a coherent framework for EPDs and for their mutual recognition, when developed under the established audited and recognised EPD Programme Operators, with a special emphasis on the construction sector.

In all these cases, EPDs are developed according to PCRs (usually system specific), that provide guidance and requirements on the LCA to be performed for a defined product category. PCRs are particularly important in defining the boundaries of the system being studied, the declared or functional unit of the study, the methodology to be used and the information to be included in the EPD.

As referred in Section 2.1, the sustainability of resources' use is also regulated by the CPR (EU, 2011), which provides harmonised rules for the marketing of construction products in the EU and refers to the use of EPDs. CPR Annex I establishes the basic requirements for construction works, including three that specifically address environmental aspects, being the last one introduced by this document. Therefore, the following should be, in some way, included in the environmental or performance declarations:

- Requirement (3): Hygiene, health and the environment;

- Requirement (5): Protection against noise;

- Requirement (7): Sustainable use of natural resources.

Furthermore, in the introduction of the CPR document (§55), it is referred that Requirement (7) also comprises the recyclability of construction works, their materials and parts after demolition, the durability of construction works and the use of environmentally compatible raw and secondary materials. It is stated that, when available, EPDs should be used to support the assessment of sustainability in resource use and the potential impact of construction works on the environment.

\subsection{PEF and applications to construction materials}

PEF is intended to be a harmonised methodology for the calculation of the environmental footprint of products (based on a life cycle thinking approach and on existing standards (Galatola and Pant, 2014). 
PEF was developed as a cross-sectorial approach, also applicable to the construction sector, which is applicable for both in-house needs (e.g. identification of environmental hotspots) and external communication (Manfredi et al., 2015). The framework of the PEF initiative is based on EC documents and political orientations that influenced the lifecycle thinking implementation policy, namely:

- The Sustainable Consumption and Production and Sustainable Industrial Policy Action Plan (Council of the European Union, 2008);

- The conclusions of the Council on sustainable materials management and sustainable production and consumption (Council of the European Union, 2010);

- The Roadmap to a Resource Efficient Europe (EC, 2011);

- The Single Market for Green Products Initiative (EC, 2013a).

Within the Single Market for Green Products Initiative, a series of activities were developed that resulted in a Commission Recommendation on the use of common methods to measure and communicate the life cycle environmental performance of products and organisations (EC, 2013b). Following the first stage of PEF and OEF methods development, a pilot phase was implemented, between 2013 and 2018 (DG Environment, 2018). From this, a series of PEF pilots were developed based on the respective PEF Category Rules (PEFCR). PEFCRs are PCR that allow a more specific set of rules and product category specific guidelines for the development of PEFs and whose main objective is to allow comparison between PEFs within the same product category (Minkov et al., 2015). The pilot phase included three products within the construction sector: decorative paints (Carasso et al., 2018), hot and cold-water supply pipes (Vollebregt et al., 2019) and thermal insulation (Ravel et al., 2019). After the conclusion of the pilot phase, the JRC gathered a set of recommendations to update the method that are expected to be officially uptaken (Zampori and Pant, 2019).

As referred and similarly to EPDs, the development of PEFs is supported by the use of specific PCR the PFCRs. However, according to ISO 14025, EPDs shall be developed and provided under an EPD programme, and subjected to the general programme instructions and particularly to the PCR. The mentioned programme is administrated by a programme Operator, such as a company, an association, public authority or agency, an independent scientific body or other organization. Considering that there is no Programme Operator nor a clear decision on how LCAs will be further used, PEF cannot be identified as an EPD scheme according to ISO 14025 (Finkbeiner, 2014).

In summary, the PEF initiative addresses the need for harmonized methods to calculate and communicate environmental information in Europe. This allows the development of a "Single Market for Green Products".

\section{Methodology}

To achieve the proposed objectives, a review was developed on the LCA methodology, its evolution and standardisation, the development of the PEF methodology and of the communication of environmental related information through EPDs. The comparison between the PEF and EPDs for construction materials is focused on the key requirements of the former, as identified in the PEF method and summarised in Annex $\mathrm{X}$ of the Commission Recommendation of 2013 (EC, 2013b) and of the latter as defined in EN 15804. These requirements are listed and analysed in Tables 1-7 and are the following ones:

- Life cycle thinking based;

- PCR development and the role of PCR;

- Communication target/audience;

- Declared unit, Unit of analysis and Reference flow;

- System boundaries and Life cycle stages;
- Cut-off;

- Modelling approach;

- Capital goods inclusion;

- Data quality assessment;

- Data type and collection;

- Dealing with data gaps;

- Allocation in multifunctionality;

- Allocation for recycling;

- Number of LCIA impact categories;

- Normalisation and weighting;

- Interpretation of results;

- Reporting;

- Review and reviewer qualifications.

For each requirement, the versions from 2013 (CEN/TC 350, 2013; EC, 2013b) and the updates from 2019 (CEN/TC 350, 2019; Zampori and Pant, 2019) were considered and are discussed in Section 4.

This work identifies efforts already developed towards harmonisation and suggests further options to promote the integration of the referred methods.

\section{Results and discussion}

The main objective of this work is to compare the two main methods and corresponding tools to assess and/or communicate the environmental performance of construction products at the European level: PEFs and EPDs. Tables 1-7 summarise the comparison between PEF method and EN 15804, similarities between them are highlighted in bold.

The PEF method is based on the existing LCA standards ((ISO, 2006b, 2006c) and on standards regarding the communication of environmental performance, namely those specific for construction products (CEN/TC, 2013; ISO / TC 59, 2007; ISO, 2006c). However, its 2013 version conflicted with the ISO and European standards on LCA for Type III labels i.e. ISO 14040, EN 15804, ISO 21930 and ISO 14025 (CEN/TC, 2013; ISO / TC 59, 2007; ISO, 2006a, 2006c) in several areas (Finkbeiner, 2014). EPDs are being developed for some years in Europe, based on ISO and European standards. EN 15804 is the most relevant in this context. While the PEF is a method for the calculation of the environmental footprint, an EPD is a communication tool for LCA study results, under a voluntary programme for verified type III environmental declarations, both referring to products (goods and services). The results presented in this study demonstrate that, even though both PEF method and EN 15804 compliant EPDs are based on the life cycle method, they are different in most of the key requirements and LCIA choices, as discussed in the following paragraphs and in Tables 1-7.

Besides key requirements to be presented and discussed, a relevant difference was found between the terminology considered in each method. Many terms were introduced by PEF that conflict with the mentioned standards, for instance: activity data instead of non-elementary flow; company-specific or site-specific data instead of primary data; and unit of analysis instead of the functional unit. These terminology discrepancies were addressed both in the suggestions for updating the PEF method and in the revision of EN 15804 standard, thus they do not persist in the latest documents of both methods.

Table 1 summarises the main general aspects compared. Although both PEF and EN 15804 require the development of PCR, the PEFCR limits the methodological options of the practitioner. For instance, the PEFCR already provides a screening step that allows refining the scope and includes the identification of secondary datasets and scenarios for the LCA stages after the manufacturing, as well as possible exclusions. The existence of a benchmark for a representative product is also a characteristic and added value of the PEFCR. This benchmark is the PEF of a representative product for that product category and allows positioning the analysed products and also the verification of the plausibility of the results. Furthermore, if it is necessary to apply cut-offs, the 
Table 1

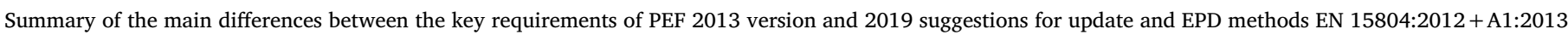
and revised - EN 15804:2012+A1:2013+A2:2019 - General aspects.

\begin{tabular}{|c|c|c|}
\hline Requirement & $\begin{array}{l}\text { EC PEF method (2013) } \\
\text { Suggestions for update (2019) }\end{array}$ & $\begin{array}{l}\text { EN 15804:2012+A1:2013; } \\
\text { EN 15804:2012+A1:2013+A2:2019 }\end{array}$ \\
\hline Life cycle thinking based & Yes & Yes \\
\hline $\begin{array}{l}\text { PCR development and role } \\
\text { of PCR }\end{array}$ & $\begin{array}{l}\text { (2013) PEFCR enables comparisons and comparative } \\
\text { assertions. Covers key areas (screening, background and } \\
\text { foreground processes, etc.) and provide benchmark } \\
\text { information. This method provides guidance on the } \\
\text { development of PEFCR and on their use. } \\
\text { (2019) This method extensively defines PEFCR development } \\
\text { requirements and includes a PEFCR template. }\end{array}$ & $\begin{array}{l}\text { EN } 158014 \text { provides core PCR for Type III environmental declarations for any } \\
\text { construction product and service. The programme operators shall develop specific } \\
\text { PCR. } \\
\text { In general, it does not enable comparisons at the product level, but only at the } \\
\text { building or assembly level. PCRs for EPDs do not have to cover areas like screening } \\
\text { foreground processes or provide benchmark information. }\end{array}$ \\
\hline Target/audience & $\begin{array}{l}\text { In house applications; } \\
\text { External applications: B2B and B2C. }\end{array}$ & B2B. \\
\hline
\end{tabular}

benchmark provides support to determine the importance of excluded flows or processes in the resulting environmental impacts. The benchmark also supports both the validation of a posterior PEF study and a better-informed decision within a green procurement process. To promote comparability of EPDs at the product level, EPD programme operators may consider a better specification of methodological choices in future versions of PCR, namely in the definition of scope and boundaries, secondary datasets and cut-off criteria. Still in Table 1, it is possible to verify that, although both LCA assessment and communication methods can be used for business-to-business B2B communication, this is really the primary objective of EN 15804 EPDs, while PEF is also intended for in house applications and business-to-consumer B2C applications. This may influence, for instance, the choice of performing cradle-to-gate studies in the case of EPDs, dedicated to provide Architecture, Engineering and Construction (AEC) professionals with information on the construction products before its application on the building. On the contrary, a final consumer would be more interested in a PEF for including the impacts of the whole life cycle of the product as it is integrated in the building.

In terms of scope, there are several differences between the two methods (Table 2). In PEF, the functional unit is to be defined not only according to the functions/services provided, but also to the magnitude, the expected level of quality and the duration/lifetime of the product. According to EN 15804, in the EPD there may be a declared unit, not depending on the product's function. The system boundaries in PEF include a cradle-to-grave approach while in EN 15804 the mandatory stages are cradle-to-gate. However, in its updated version, EN 15804 also foresees the declaration of all stages of the products' life cycle. It is controversial that it makes sense to include all life cycle stages in the analysis of a product with such a long-expected service life, sometimes 50 years or more, considering all the uncertainty of the use and end-oflife stages. However, if the scenarios are fixed, this will increase comparability. The scope of the two methods was harmonised with the revision of EN 15804, which now foresees a clear preference for a functional unit instead of a declared one, although the basis for the definition of the functional unit are still not perfectly aligned, and PEF is more specific in the requirements for this definition. The system boundaries also evolve towards harmonisation, with cradle-to-grave approach to be applied in both methods.

In the PEF method, the modelling options are limited to the guidelines of the applicable PEFCR. The current PEF method does not allow cut-offs and there are several LCA experts that do not agree with this approach (Bach et al., 2018; Finkbeiner, 2014; Minkov et al., 2015). Therefore, this situation is better specified in the suggestions to update the PEF method. The suggestions state that, as a base rule, it is not possible to consider cut-offs during the screening step and that all available information should be considered in an LCA study. If it is not possible to consider all information, cut-offs are allowed based on specific rules detailed in the PEFCRs depending on the significance of neglected flows for the potential impacts. Thus, cut-offs are allowed only after the screening step and based on the significance of the potential environmental impacts of the excluded flows. In EN 15804, the cut-off rule is based on the share of the excluded mass or energy flows. This aspect is not directly comparable, but the low percentage of allowed exclusions should ensure that differences in the obtained results are not significant. Still related to the modelling options, while PEF applies elements from both attributional and consequential approaches, EN 15804 is attributional. The revision of EN 15804 and the end-of-life allocation harmonised this aspect with the PEF approach, since EPD will also apply elements from both attributional and consequential approaches.

In the life cycle inventory or resource use and emissions profile of both methods, the data quality assessment overall covers the same aspects (Table 3). Both in the revision of EN 15804 and in the suggestions for updating the PEF Method, a quantitative quality assessment method is established. Sources of secondary data are more restricted in PEF, since, according to the updating suggestions, if no Environmental Footprint compliant (EF-compliant) or ILCD-EL compliant proxy is available, then the process shall be excluded from the model. This is an aspect in which the PEF method should be developed to be more harmonised with EN 15804: in the absence of EF-compliant or ILCD-EL compliant proxy, other scientifically validated databases should be allowed as a proxy, even if this situation is reported as a limitation of the LCA study.

Regarding the guidelines for multi-functionality allocation, the hierarchy for choice is similar (Table 4). The main difference is that in PEF system expansion is within the first option along with subdivision. In EPDs, according to EN 15804, the system boundary expansion is not applied. This would conflict with the rationale of attributional LCA used in EPDs (Del Borghi et al., 2019). For the EOL allocation, the PEF Guide proposes a specific recycling allocation equation to calculate the Resource Use and Emissions Profile (RUaEP) based on the benefits accounting of using recycled materials and recycling at the end-of-life phase of a product. EN 15804 considers this allocation differently, setting the system boundary at the point the end-of-waste state is reached. This way, the potential impacts of the waste treatment processes are assigned to the product system that generates it. In its revised version, EN 15804 sets the same approach for the EOL allocation as the PEF method, again harmonising the methodological choices.

Concerning LCIA, a big discrepancy was identified between the impact categories analysed (Table 5), and the characterisation methods used in both methods (Table 6). However, in the calculation of midpoint impact indicators, the revision of EN 15804 is aligning the LCIA methods with the ones used in the PEF methodology (Table 6). Considering that decision-making is an objective of the use of LCA studies for the construction products, as well as the fact that the users of the LCA results are not experts, the increase in the number of indicators may cause some misunderstanding in the analysis of results. Moreover, to facilitate $\mathrm{B} 2 \mathrm{C}$ communication, the PEF allows the calculation of single indicators through the normalisation and weighting steps of the 
Table 2

Summary of the main differences between the key requirements of PEF 2013 version and 2019 suggestions for update and EPD methods EN 15804:2012+A1:2013 and revised - EN 15804:2012 + A1:2013 + A2:2019 - Scope and boundaries.

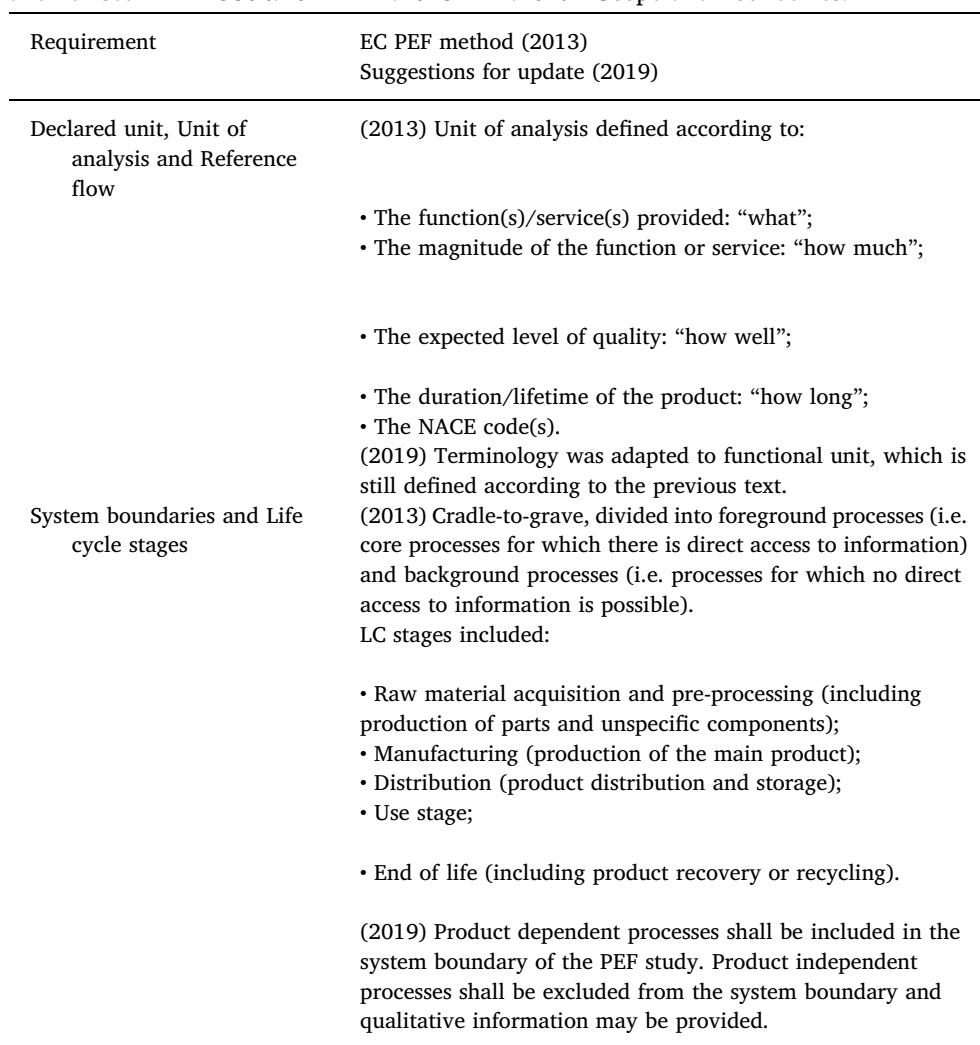

EN 15804:2012+A1:2013;
EN 15804:2012+A1:2013+A2:2019

(2013) The declared unit may be used instead of the functional unit when the precise function of the product or scenarios at the building level is not stated or is unknown.

If a functional unit is used, it is based on:

- The quantified, relevant functional use or performance characteristics of the construction product when integrated into a building, taking into account the functional equivalent of the building;

- The product's Reference Service Life or required service life of the under defined in-use conditions.

(2019) The declared unit shall be applied if a functional unit cannot be defined.

(2013) Mandatory: Cradle-to-gate (Modules A1-A3):

- Extraction and processing of raw materials and secondary material input processing (A1);

- Transportation (A2) to the manufacturer;

- Production (A3);

- Other life cycle stages may be declared.

(2019) For all construction products and materials the following LC stages shall be declared:

- Raw materials supply (A1)

- Transport (A2)

- Manufacturing (A3)

- Deconstruction/demolition (C1);

- Transport (C2);

- Waste processing (C3);

- Disposal (C4);

- Benefits and loads beyond the system boundaries (D).

Modules C1-C4 and module D may be omitted for products which fulfil all three of the conditions below:

- The product or material is physically integrated with other products during installation, so they cannot be physically separated from them at the end of life, and

- The product or material is no longer identifiable at the end of life as a result of a physical or chemical transformation process, and

- The product or material does not contain biogenic carbon.

In case of insufficient input data or data gaps for a unit process, the cut-off criteria shall be $1 \%$ of renewable and non-renewable primary energy use and $1 \%$ of the total mass input of that unit process. The total of neglected input flows per module, e.g. per module A, B, C or D shall be a maximum of $5 \%$ of energy use and mass.

(2019) Processes and elementary flows may be excluded up to $3.0 \%$, based on material and energy flows and on the level of environmental significance (single overall score) - previous screening process.

Modelling approach Applies elements from both attributional and consequential approaches.

Capital goods inclusion

(2013) capital goods included.

(2019) it excludes capital goods and their infrastructures unless proven relevant.

(2013) Attributional.

(2019) Applies elements from both attributional and consequential approaches. Not specified.

LCIA, but this is not allowed in the EPD method, according to the rules set in the EN 15804 standard. Although facilitating the understanding and direct comparison potential of the reported results, these steps, especially weighting, add subjectivity to the analysis and disregards the variability of the weighting factors depending, for instance, on geographic location.

According to the PEF guide, interpretation of results has strict guidelines for the identification of hotspots, while having specifications also for the estimation of uncertainty and conclusions, limitations and recommendations (Table 7). In the EN 15804, there are no specific recommendations on the interpretation of results. However, the application of the PEF guidelines' principles to the LCA project report that supports the development of EPDs is another harmonisation suggestion. This option may increase the usability of LCA results both for internal identification of hotspots and process improvement and external uses like communication of most relevant impacts, uncertainty, etc.

In PEF method and in EN 15804, there are specific guidelines to report the results. One big difference in this requirement is that the PEF report is public, while in the case of EPDs the declaration is public, but the report may be confidential, provided only to the system operator 
Table 3

Summary of the main differences between the key requirements of PEF 2013 version and 2019 suggestions for update and EPD methods EN 15804:2012 + A1:2013 and revised - EN 15804:2012 + A1:2013 + A2:2019 - LCI data.

\begin{tabular}{ll}
\hline Requirement & $\begin{array}{l}\text { EC PEF method (2013) } \\
\text { Suggestions for update (2019) }\end{array}$ \\
\hline $\begin{array}{c}\text { Data quality } \\
\text { assessment }\end{array}$ & Technological representativeness; \\
& - Geographical representativeness; \\
& Time-related representativeness; \\
& \\
& - Completeness; \\
- Parameter uncertainty; & Methodological appropriateness and consistency: for processes or \\
& activities accounting for 70\% of contributions to each impact \\
& category, data shall be quantitatively assessed and achieve at least \\
an overall "good quality" level. \\
(2019) Implementation of Data Needs Matrix (to evaluate data \\
requirements); Data quality ratings.
\end{tabular}

\begin{abstract}
Data type and (2013) Specific data: for all foreground processes and for collection background processes, where appropriate.
\end{abstract}

Generic data: only for processes in the background system, unless (generic data) are more representative or appropriate than specific data for foreground processes. They shall be sourced from:

- Data developed in line with the relevant PEFCRs;

- Data developed in line with the requirements for PEF studies; - ILCD Data Network;

- ELCD.

(2019) Implementation of a refined hierarchy:

- Use an Environmental Footprint (EF) -compliant proxy;

- Use an ILCD entry level (EL) compliant proxy;

- If no EF-compliant or ILCD-EL compliant proxy is available, then the process shall be excluded from the model (reported as a data gap and validated by the verifier).

Dealing with data (2013) Any data gaps shall be filled using best available generic or extrapolated data and shall not account for more than $10 \%$ of the overall contribution to each impact category considered, based on the initial screening.

(2019) Data gaps shall be filled only with EF-compliant or ILCD-EL compliant proxy. If no EF-compliant or ILCD-EL compliant proxy is available, then the process shall be excluded from the model.
EN 15804:2012+A1:2013; EN 15804:2012+A1:2013+A2:2019

- Technology coverage shall reflect the physical reality;

- Geographical coverage;

- Time-related coverage (as current as possible (updated within 10 years for generic data and 5 years for specific data); 1 -year averaged data to be used; the time period over which inputs to and outputs from the system shall be accounted for shall be 100 years);

- Completeness;

- Precision;

- Consistency;

- Sources of the data.

(2019) It also specifies the possibility of using one of two following data quality assessment systems (UN Environment Global Guidance on LCA or PEF method assessment systems).

(2013) Primary data: First choice: specific + average data. However, (CEN/TR 15941:2010) generic data may also be used to refer to the manufacturer's own process (on site).

Secondary data: Data from other sources such as literature or databases may be used for the processes the producer cannot influence; documentation of technological, geographical and time-related representativeness shall be provided. No specific data source is recommended. The practitioner must follow the defined data quality requirements to select secondary data (Silvestre et al., 2015).

(2019) Terminology was adapted to specific and generic data. The documentation format and datasets for the LC inventory data used in the LCA modelling shall use the current ILCD format and nomenclature.

In case of insufficient data or data gaps for a unit process, it may be filled by conservative assumptions with average or generic data. If not possible, cut-offs allowed are described earlier in this table. and verifiers. Reporting feeds the verification step. According to the PEF Guide, any PEF study intended for internal communication claiming to be in line with the PEF Guide, and any PEF study for external communication e.g. B2B or B2C, shall be critically reviewed through an independent external review process. There are specific requirements for verifiers and, if a single person does not fulfil all requirements, more verifiers shall join the verification team until the total number of mandatory requirements is fulfilled. In the case of EPDs, verification is mandatory if the EPD is to be registered under an EPD programme. The programme operator establishes the verification checklist and requirements for verifiers, as well as a pool of independent verifiers, but there are no specific requirements for the verifiers. In this case, the existence of requirements for the verifiers could bring more transparency in the selection of the pool of verifiers, and it could be another convergence possibility to be considered.

\section{Conclusions}

The main objective of this work was to compare the two main tools to assess and communicate the environmental performance of construction products at the European level, the PEF method and the
European standard 158014, for the development of EPDs. The results of the analysis performed show that, in their 2013 versions in force at the beginning of the study, there were important methodological divergences between these methods. These divergences were, however, overcome with the publication of the updated PEF method and, mostly, with the 2019 revised version of EN 15804. Harmonisation happened, for instance, in the boundaries of the LCA study, end-of-life allocation, data quality requirements and on the LCIA, i. e. the considered impact categories and used characterisation methods.

Nevertheless, it was concluded that so far existing EPDs and PEFs (or the benchmarks, PEF results for a representative product of the product category, available in PEFCRs) cannot be compared for the same material in the form they are currently established. Thus, for decision-making, stakeholders cannot compare results from both methods

For the EPD programmes framed by EN 15804, the standard refers that EPDs are tools that can provide a comparison between construction products or services in the context of their application in a building. Comparability between EPDs developed for the same category of products or for products that fulfil the same function at the building or assembly level is straightforward since the EPDs present the 
Table 4

Summary of the main differences between the key requirements of PEF 2013 version and 2019 suggestions for update and EPD methods EN 15804:2012 + A1:2013 and revised - EN 15804:2012 + A1:2013 + A2:2019 - Allocation.

\begin{tabular}{ll}
\hline Requirement & $\begin{array}{l}\text { EC PEF method (2013) } \\
\text { Suggestions for update (2019) }\end{array}$ \\
\hline Allocation in multifunctionality & $\begin{array}{l}\text { Hierarchy: } \\
\text { (1) Subdivision or system expansion; }\end{array}$ \\
& $\begin{array}{l}\text { (2) Allocation based on a relevant underlying physical } \\
\text { relationship (substitution may apply here); } \\
\text { (3) Allocation based on some other relationship. }\end{array}$
\end{tabular}

EN 15804:2012+A1:2013; EN 15804:2012+A1:2013+A2:2019

(2013) Hierarchy:

(1) Avoidance of allocation by subdivision: dividing the unit process to be allocated into different subprocesses that can be allocated to the co-products;

(2) If no data on sub-processes is available for subdivision, then partitioning reflecting the underlying physical relationship;

(3) Allocation based on physical properties when the difference in revenue from the co-products is low; in all other cases, it shall be based on economic values (exception: material flows carrying specific inherent properties shall always be allocated reflecting the physical flows, irrespective of the allocation chosen for the process).

(2019) Calorific content, composition [biogenic carbon content, $\mathrm{CaO} / \mathrm{Ca}(\mathrm{OH})_{2}$ content, etc.], shall not be allocated but always reflect the physical flows.

Allocation for Recycling (2013) Specific guidance (including formulae) provided, also accounting for energy recovery. EOL allocation formula is provided based on the 50:50 approach.

(2013) End of Life (EOL) system boundary: until the end-of-waste state is reached: EOL treatment including recovery or recycling processes is assigned to the product system that generates the waste. If further processing is needed to be introduced in another product system, this is considered to be beyond the system boundary and are assigned to the optional informative module D (Silvestre et al., 2014).

(2019) New formula for harmonised approach: the Circular Footprint Formula (CFF), which is a combination of "material + energy + disposal".

information in an objective and uniform way. However, this situation can be compromised by methodological choices during the LCA study or by choice of different databases for secondary information. In the case of the PEF method, comparability is clearly stated as an objective. Therefore, there are clear guidelines for the background data to be used and for the scenarios to apply, for instance in the case of end-of-life stages, ensuring that comparability focuses on specificities of the product or manufacturer and is not biased by an external factor or inadequate use of background information.

At the moment there is a great effort on the harmonisation of coexisting LCA calculation and reporting methods, including PEF and EN 15804, and of the several EPD schemes currently operating. The implementation of the suggestions to update the PEF method (Zampori and Pant, 2019) and the current proposal for revising the European standard EN 15804 (CEN/TC 350, 2019) will make both methods for the construction sector closer and facilitate the integration of environmental information provided by each of them. Nevertheless, even with the efforts to update the methods, EN 15804 cannot be yet completely replaced with PEF. The reasoning for this is that although PEF shall provide very strict PEFCRs, it is still a global method within the Single Market for Green Products. At the same time, EN 15804 is a PCR for the construction sector, also implying that program operators need to develop the specific PCR for the different types of construction products.
Additionally, EN 15804 is still the only method that takes into account some specificities of the construction sector, such as the fact that construction products or assemblies are to be part of a building and are not final products. Another critical limitation of PEF, compared to EN 15804 , is that, without a program operator, it is not clear who ensures the quality of the LCA study and the transparency of the process. For now, there are no construction products' EPDs nor PEFs or benchmarks developed according to the updated methods. Therefore, it is not possible to compare what the convergence of the results would be if the updates were applied.

It is important to acknowledge the relevance that EPDs already have in the construction sector, since they are still widely used (Ibáñez-Forés et al., 2016). There are numerous EPDs currently published and probably a lot more that are still being developed during the transition phase to the revised version of the EN 15804 standard. The update of the EN 15804 will imply a change in the methodology applied in the LCA study and also in the environmental information declared. This implies that results shall be carefully interpreted in order to identify what standards or regulations were considered in each study. However, existing EPDs are valid until their expiration date, so manufacturers may delay the investment in the update of their EPDs until then. This may happen even later, if that date occurs at an early stage of the transition phase and the programme operator does not yet provide

Table 5

Summary of the main differences between the key requirements of PEF 2013 version and 2019 suggestions for update and EPD methods EN 15804:2012 + A1:2013 and revised - EN 15804:2012 + A1:2013 + A2:2019 - Impact assessment.

\begin{tabular}{|c|c|c|}
\hline \multirow[t]{2}{*}{ Requirement } & EC PEF method (2013) & \multirow{2}{*}{$\begin{array}{l}\text { EN 15804:2012+A1:2013; } \\
\text { EN 15804:2012+A1:2013+A2:2019 }\end{array}$} \\
\hline & Suggestions for update (2019) & \\
\hline $\begin{array}{l}\text { Nr. of LCIA impact } \\
\text { categories }\end{array}$ & (2013) 14 & (2013) 7 \\
\hline (see Table 2) & (2019) 16 (with subdivisions) & (2019) 13 core indicators +6 additional indicators \\
\hline $\begin{array}{l}\text { Normalisation and } \\
\text { weighting }\end{array}$ & $\begin{array}{l}\text { (2013) Not required. If applied, methods and results shall be reported } \\
\text { under "additional environmental information". } \\
\text { (2019) Following the steps of classification and } \\
\text { characterisation, the EF impact assessment shall be } \\
\text { complemented with normalisation and weighting. }\end{array}$ & $\begin{array}{l}\text { No normalisation or weighting: impact assessment; includes only } \\
\text { classification and characterisation steps. }\end{array}$ \\
\hline Interpretation of results & $\begin{array}{l}\text { Assessment of the robustness of the PEF model, identification of hotspots, } \\
\text { estimation of uncertainty and conclusions, limitations and } \\
\text { recommendations are mandatory. Specific guidelines, namely for the } \\
\text { identification of the most relevant impact categories, life cycle stages, } \\
\text { processes and elementary flows. }\end{array}$ & $\begin{array}{l}\text { No identification of hotspots nor recommendations required, because it is } \\
\text { not required to be declared (interesting mainly for in house uses). }\end{array}$ \\
\hline
\end{tabular}




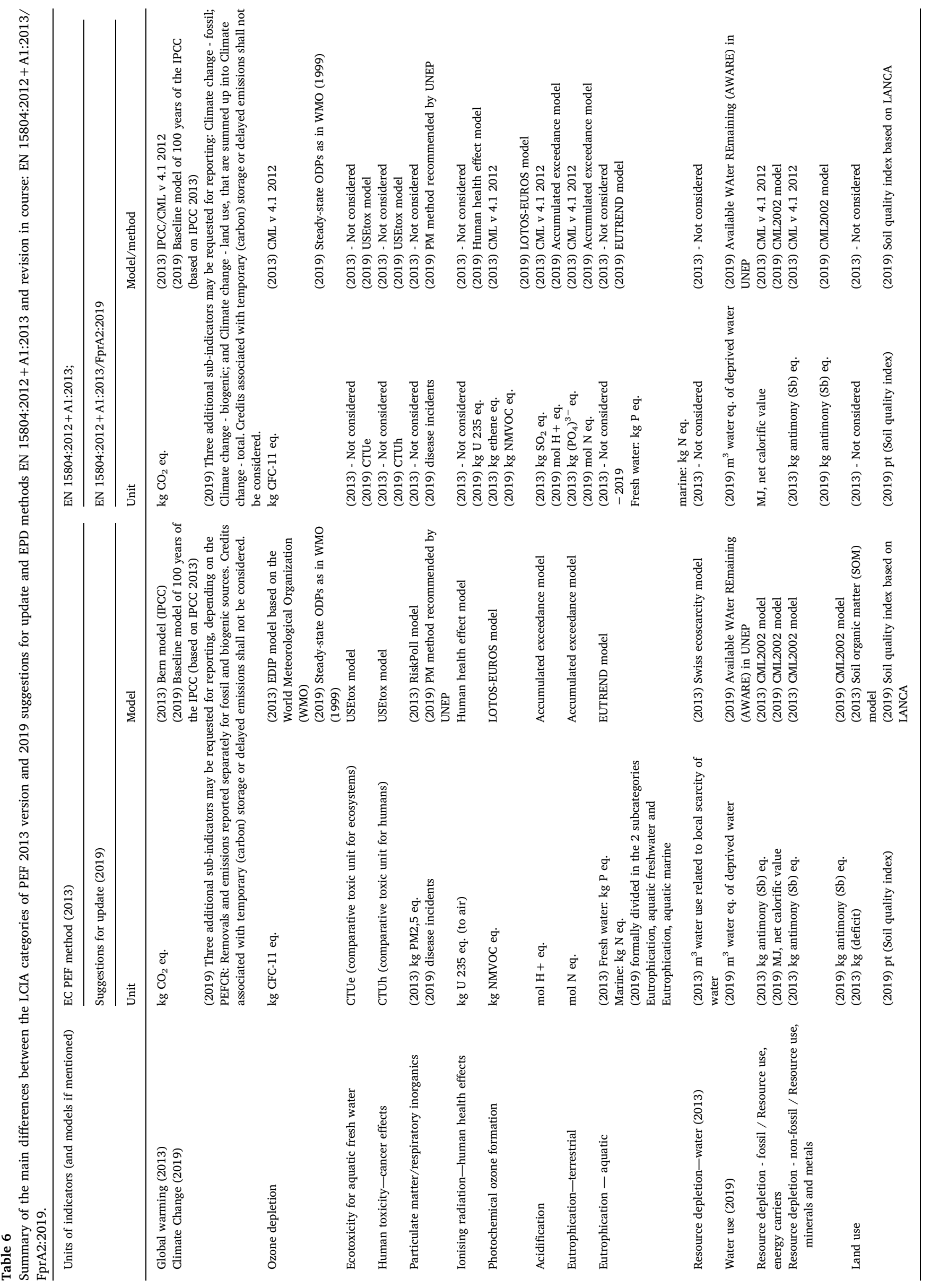


Table 7

Summary of the main differences between the key requirements of PEF 2013 version and 2019 suggestions for update and EPD methods EN 15804:2012+A1:2013 and revised - EN 15804:2012 + A1:2013 + A2:2019 - Reporting and reviewing.

\begin{tabular}{|c|c|c|}
\hline Requirement & EC PEF method (2013) Suggestions for update (2019) & EN 15804:2012+A1:2013; EN 15804:2012 + A1:2013 + A2:2019 \\
\hline Reporting & $\begin{array}{l}\text { The study report shall include, at least, a Summary, a Main } \\
\text { Report, and an Annex. These shall contain all the elements } \\
\text { specified. Any additional supporting information can be } \\
\text { included, e.g. a Confidential Report (The content of these } \\
\text { mandatory reporting elements closely follows ISO } 14044 \\
\text { requirements on reporting. However, if the assessment supports } \\
\text { comparative assertions (to be disclosed to the public), ISO } \\
\text { reporting requirements go beyond PEF reporting requirements). }\end{array}$ & $\begin{array}{l}\text { It provides general requirements for reporting and additional requirements for } \\
\text { third-party reporting. EPD is publicly disclosed but complete project report shall } \\
\text { be made available to the verifier with the requirements on confidentiality stated } \\
\text { in EN ISO } 14025 \text {. }\end{array}$ \\
\hline $\begin{array}{c}\text { Review and reviewer } \\
\text { qualifications }\end{array}$ & $\begin{array}{l}\text { Unless otherwise specified, any study intended for external } \\
\text { communication shall be reviewed by an independent and } \\
\text { qualified external reviewer (or review team). A study to support } \\
\text { a comparative assertion intended to be disclosed to the public } \\
\text { shall be based on relevant PEFCRs and reviewed by an } \\
\text { independent external reviewer together with a stakeholder } \\
\text { panel. Minimum requirements for reviewer qualifications } \\
\text { apply. }\end{array}$ & $\begin{array}{l}\text { Programme Operator is responsible for the establishment of an independent } \\
\text { verifier selection (and definition of minimum requirements) and transparent } \\
\text { verification procedure. }\end{array}$ \\
\hline
\end{tabular}

updated PCRs. During the transition phase to the revised standard, programme operators shall work on the update of their systems, PCRs and further requirements applicable so that, at the end of this phase, the revised standard is completely implemented. Meanwhile, it is crucial that stakeholders like EPD programme operators, LCA practitioners, manufacturers recognise the differences and are aware that results are not comparable for studies performed according to distinct methods, even if only PEF or EPD are being compared but were not developed according to the same standard.

The harmonisation of the LCA method and of the communication of the environmental performance will support both green procurement and the overall pursuit for sustainability in all sectors, and specifically in the construction sector.

\section{Declaration of Competing Interest}

None.

\section{Funding}

This work was supported by FCT - Fundação para a Ciência e Tecnologia [grant number PD/BD/127852/2016] under the Doctoral Program EcoCoRe - Eco-Construction and Rehabilitation. Support from CERIS and Instituto Superior Técnico is also acknowledged.

\section{References}

Bach, V., Lehmann, A., Görmer, M., Finkbeiner, M., 2018. Product environmental footprint (PEF) pilot phase-comparability over flexibility? Sustainability 10, 1-18. https://doi.org/10.3390/su10082898.

Carasso, E., Dolla, O., van der Meulen, J., Alvarado, C., Brunt, D., Klaasen, R., Sonnen, M., Trescol, J., Demaine, R., Schön, B., Gade, L., Verlhac, P., Overzier, B., Percy, M., Schtiza, A., Castelan, G., Grochal, P., 2018. Product Environmental Footprint Category Rules - Decorative Paints. Technical Secretariat Decorative Paints, Brussels.

CEN/TC 350, 2019. Sustainability of Construction Works - Environmental Product Declarations - Core Rules for the Product Category of Construction Products. EN 15804:2012 + A1:2013/FprA2:2019.

CEN/TC 350, 2001. Sustainability of Construction Works - Environmental Product Declarations - Communication Format Business-to-business. EN 15942:2011.

CEN/TC 350, 2011a. Sustainability of Construction Works -Assessment of Buildings - Part 2: Framework for the Assessment of Environmental Performance. EN 15643-2. .

CEN/TC 350, 2011b. Sustainability of Construction Works -Assessment of Environmental Performance of Buildings -Calculation Method. EN 15978:2011. .

CEN/TC 350, 2012a. Sustainability of Construction Works -Assessment of Buildings - Part 3: Framework for the Assessment of Social Performance. EN 15643-3. .

CEN/TC 350, 2012b. Sustainability of Construction Works -Assessment of Buildings - Part 4: Framework for the Assessment of Economic Performance. EN 15643-4. .

CEN/TC 350, 2013. Sustainability of Construction Works - Environmental Product Declarations - Core Rules for the Product Category of Construction Products. EN $15804: 2012+\mathrm{A} 1: 2013$.

Council of the European Union, 2008. Sustainable Consumption and Production and
Sustainable Industrial Policy Action Plan-council Conclusions. Brussels. .

Council of the European Union, 2010. Council Conclusions on Sustainable Materials Management and Sustainable Production and Consumption: Key Contribution to a Resource-efficient Europe, in: 3061st ENVIRONMENT Council Meeting. Council of the European Union, Brussels, pp. 1-6.

Del Borghi, A., Moreschi, L., Gallo, M., 2019. Communication through ecolabels: how discrepancies between the EU PEF and EPD schemes could affect outcome consistency. Int. J. Life Cycle Assess. 1-16. https://doi.org/10.1007/s11367-01901609-7.

Dolezal, F., Boogman, P., 2016. Current state of the discussion between pef and epd as the preferable life cycle assessment scheme for wooden construction products. COST Action FP 1407 2nd Conference: Innovative Production Technologies and Increased Wood Products Recycling and Reuse. Brno, Czech republic.

EC, 2011. Communication From the Commission to the European Parliament, the Council, the European Economic and Social Committee and the Committee of the Regions: Roadmap to a Resource Efficient Europe Roadmap to a Resource Efficient Europe, 20.9.2011. Brussels, Belgium. .

EC, 2012. Communication From the Comm to the European Parliament and the Council: Strategy for the Sustainable Competitiveness of the Construction Sector and Its Enterprises. European Commission, Brussels, Belgium.

EC, 2013a. Communication From the Commission to the European Parliament and the Council: Building the Single Market for Green Products - Facilitating Better Information on the Environmental Performance of Products and Organisations. European Commission, Brussels, Belgium.

EC, 2013b. Commission Recomendation of 9 April 2013 on the use of common methods to measure and communicate the life cycle environmental performance of products and organisations, Brussels, Belgium. Official Journal of the European Union (L124), $1-210$.

EC, 2014. Communication From the Commission to the European Parliament, the Council, the European Economic and Social Committee and the Committee of the Regions: Resource Efficiency Opportunities in the Building S Ector. European Commission, Brussels, Belgium.

EC - JRC, 2010. ILCD Handbook: General Guide for Life Cycle Assessment -Detailed Guidance, 1st editio. Publications Office of the European Union: European Commission, Luxembourg. https://doi.org/10.2788/38479.

Eco Platform, 2019. Eco Platform [WWW Document]. http://www.eco-platform.org/ home.html (accessed 11.6.19).

EU, 2011. Regulation (EU) No 305/2011 of the European Parliament and of the Council of 9 March 2011 on the Construction Products Regulation (CPR). Official J. European Union European Parliament, European Union Council (L088), 5-43.

Finkbeiner, M., 2014. Product environmental footprint - Breakthrough or breakdown for policy implementation of life cycle assessment? Int. J. Life Cycle Assess. Jpn. 19 (2), 266-271. https://doi.org/10.1007/s11367-013-0678-x.

Galatola, M., Pant, R., 2014. Reply to the Editorial "product Environmental Footprint Breakthrough or Breakdown for Policy Implementation of Life Cycle Assessment? Prof. Finkbeiner (Int J Life Cycle Assess 19(2):266-271). Int. J. Life Cycle Assess. https://doi.org/10.1007/s11367-014-0740-3.

Gelowitz, M.D.C., McArthur, J.J., 2017. Comparison of type III environmental product declarations for construction products: material sourcing and harmonization evaluation. J. Clean. Prod. 157, 125-133. https://doi.org/10.1016/J.JCLEPRO.2017.04. 133.

Guinée, J.B., Heijungs, R., Huppes, G., Zamagni, A., Masoni, P., Buonamici, R., Ekvall, T., Rydberg, T., 2010. Life cycle assessment: past, present, and future. Environ. Sci. Technol. 45, 90-96. https://doi.org/10.1021/es101316v.

Ibáñez-Forés, V., Pacheco-Blanco, B., Capuz-Rizo, S.F., Bovea, M.D., 2016. Environmental Product Declarations: exploring their evolution and the factors affecting their demand in Europe. J. Clean. Prod. 116, 157-169. https://doi.org/10.1016/J.JCLEPRO. 2015.12.078.

ISO, 2006a. Environmental Management — Life Cycle Assessment — Principles and Framework. ISO 14040:2006. International Standisation Organisation. International 
Organization for Standardization, Geneve.

ISO, 2006b. Fnvironmental management - life cycle assessment - requirements and guidelines. ISO 14044:2006. International Standisation Organisation. International Organization for Standardization, Geneve.

ISO, 2006c. Environmental Labels and Declarations — Type III Environmental Declarations - Principles and Procedures. ISO 14025:2006.

ISO/TC 59, 2007. Sustainability in Building Construction — Environmental Declaration of Building Products. ISO 21930:2007. .

ISO/TC 59, S. 17, 2017. Sustainability in Buildings and Civil Engineering Works - Core Rules for Environmental Product Declarations of Construction Products and Services. ISO 21930:2017.

Manfredi, S., Allacker, K., Pelletier, N., Schau, E., Chomkhamsri, K., Pant, R., Pennington, D., 2015. Comparing the European Commission product environmental footprint method with other environmental accounting methods. Int. J. Life Cycle Assess. 20, 389-404. https://doi.org/10.1007/s11367-014-0839-6.

Mazeffa, D., 2017. Programme Operator Consortium. Available at: programoperators. org/wp-content/uploads/2017/10/POC_ISO-21930-Webinar_Final.pdf, accessed 2019-11-07.

Minkov, N., Schneider, L., Lehmann, A., Finkbeiner, M., 2015. Type III Environmental Declaration Programmes and harmonization of product category rules: status quo and practical challenges. J. Clean. Prod. 94, 235-246. https://doi.org/10.1016/J. JCLEPRO. 2015.02.012.

Mudgal, S., Muehmel, K., Kong, M.A., Labouze, E., Gerstetter, C., Ohlendorf, N.M., Preuss, M., Mercier, E., Rey-Coquais, E., 2012. Study on different options for communicating environmental information for products. Final report prepared for the European Commission - DG Environment.
Passer, A., Lasvaux, S., Allacker, K., De Lathauwer, D., Spirinckx, C., Wittstock, B., Kellenberger, D., Gschösser, F., Wall, J., Wallbaum, H., 2015. Environmental product declarations entering the building sector: critical reflections based on 5 to 10 years experience in different European countries. Int. J. Life Cycle Assess. 20 (9), 1199-1212. https://doi.org/10.1007/s11367-015-0926-3.

Ravel, P., Gross, L., Typpö, P., Meuwissen, E., Vitse, P., Boogman, P., Allacker, K., Adibi, N., de Hults, Q., Castelan, G., Loebel, O., Duvielguerbigny, A., Kotaji, S., van der Burgh, F., Van de moorte, E., 2019. Product environmental footprint category rules (PEFCR) for thermal insulation products in buildings. Technical Secretariat of the PEF pilot on thermal insulation in buildings. Brussels.

Ströbele, B., Lützkendorf, T., 2019. Communicating environmental information: rethinking options for construction products. Build. Res. Inf. 47, 681-696. https://doi. org/10.1080/09613218.2018.1521191.

Subramanian, V., Ingwersen, W., Hensler, C., Collie, H., 2012. Comparing product category rules from different programmes: Learned outcomes towards global alignment. Int. J. Life Cycle Assess. 17, 892-903. https://doi.org/10.1007/s11367-012-0419-6.

Vollebregt, B., Schuster, B., Fischer, G., Topalli, C., Harget, D., Gravier, E., Taubert, G., Stimmelmayr, H., Cernnajs, J., Aho, I., Bannert, O., Aranyi, S., Sejersen, P., Calton, T., Debever, L., Davidovski, Z., Sevenster, A., Castelan, G., Van-Grambezen, P., Furfari, A., Spirinckx, C., Peeters, K., Thuring, M., 2019. Product environmental footprint category rules (PEFCR) for hot and cold water supply plastic piping systems in the building. Technical Secretariat of the PEF Pilot on Hot and Cold Water Supply Plastic Piping Systems in the Building. Brussels.

Zampori, L., Pant, R., 2019. Suggestions for Updating the Product Environmental Footprint (PEF) Method. Publications Office of the EU, Luxembourg. https://doi.org/ $10.2760 / 424613$ 